Revista de Comunicación y Salud, 2018, Vol. 8, n 2, pp. 21-39

Editado por Cátedra de Comunicación y Salud

ISSN: 2173-1675

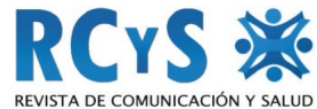

Enviado 19 de octubre de 2018

Aprobado 22 de noviembre de 2018

\title{
PREJUICIOS Y ESTEREOTIPOS EN EL CINE SOBRE TRASTORNOS ALIMENTARIOS
}

Prejudices and stereotypes on eating disorders on cinema

\author{
María Lara Martínez 1 \\ Universidad Complutense de Madrid
}

Antonio Lara Martínez

Universidad Rey Juan Carlos

\section{Resumen}

El conocimiento de la población general sobre los trastornos alimentarios es deficiente, pues al igual que con otras patologías mentales se mezclan la desinformación, los prejuicios y los estereotipos sin profundizar en las raíces de la enfermedad. Los medios audiovisuales suelen ser un reflejo de esta actitud, y a la vez son parte del problema, porque al reproducir los mismos conceptos terminan por reforzar idénticas ideas a las esperadas por los espectadores. En este artículo se estudian cuáles son las corrientes de pensamiento dominantes en el cine comercial de los últimos 20 años, analizando aquellos filmes cuyo argumento se centra en trastornos alimentarios, para confirmar si esta hipótesis es correcta.

Palabras clave: trastornos alimentarios, anorexia nerviosa, bulimia nerviosa, cine.

\section{Abstract}

The general knowledge of the population about the eating disorders is scarce. As with other mental pathologies, the misinformation, the prejudices and stereotypes are mixed without paying attention to the roots of the disease. The media are usually a reflection of this attitude, and at the same time they are part of the problem, because reproducing the same concepts they end up reinforcing identical ideas to those expected by the spectators. In this article, we study the dominant trends of thought in the commercial cinema of the last 20 years, analyzing films whose plot focuses on eating disorders, to confirm if this hypothesis is correct.

Keywords: eating disorders, anorexia, bulimia, cinema.

\section{Cómo citar el artículo}

Lara Martínez, M. y Lara Martínez, A. (2018). Prejuicios y estereotipos en el cine sobre trastornos alimentarios. Revista de Comunicación y Salud, 8(2), 21-39.

doi: http://doi.org/10.35669/revistadecomunicacionysalud.2018.8(2).21-39

\footnotetext{
${ }^{1}$ Autor para correspondencia: María Lara Martínez mlara04@ucm.es
} 


\section{INTRODUCCIÓN}

Los trastornos alimentarios no son una enfermedad única sino un complejo grupo de dolencias de diferente origen, y con manifestaciones muy diversas en cada individuo. Como suele suceder con otras patologías, o con la conducta humana en general, en el audiovisual es muy complicado abordar el problema con el detalle y rigor de una consulta médica, por lo que se reproducen los mismos errores, prejuicios y estereotipos que dominan en el imaginario colectivo. A su vez, cuando el público recibe esos estereotipos, sin matices, sin explicaciones extra, lo que se produce es un refuerzo de las ideas preconcebidas en un círculo vicioso de difícil ruptura.

La locura es muy atractiva para el arte. Cuando además el comportamiento extraño o directamente autodestructivo, se conjuga con cambios físicos, resulta una tentación para los creadores de historias. Aun así, la presentación de argumentos con trastornos alimentarios no es abundante, desde luego el porcentaje de aparición es menor que en la vida real, donde su alcance resulta muy preocupante. Quizás la razón sea que, por encima de las diferencias que cada enfermedad concreta presenta (bulimia, anorexia...), el síntoma más universal es una infinita tristeza. Y esto es más difícil de vender. Aunque la protagonista sea una modelo bellísima y escultural, es decir, el prototipo de personaje ideal según la mercadotecnia actual, si su problema le lleva a la depresión, la ansiedad y a la incomunicación, entonces la historia se vuelve demasiado intensa, demasiado real. En ese caso el personaje se suele relegar a una trama secundaria, de forma que con unas cuantas pinceladas se resuelve su caso.

En esta investigación se pretende hacer una revisión de los principales ejemplos que se encuentran en los productos cinematográficos de los últimos veinte años. Dada la extensión de la muestra no se puede ser exhaustivo, por lo que se opta desde el principio por limitarse a los ejemplos más relevantes: bien por su trascendencia, medida a través de su repercusión en taquilla, o según su alcance mediático. Para tener un referente con el que comparar esos elementos, también se han elegido ciertas obras procedentes del ámbito de cine independiente y otras premiadas con galardones de prestigio, que pueden permitirse otras licencias con más libertad que el cine comercial. Por último, la muestra se completa con varios documentales que han superado los límites del circuito habitual, y que han llegado a un grupo de espectadores mucho mayor de lo acostumbrado en este tipo de productos.

\subsection{Marco teórico}

A pesar de la controvertida acogida que tuvo en 2013 en la comunidad científica y en los medios de comunicación la $5^{\mathrm{a}}$ edición del Manual diagnóstico y estadístico de los trastornos mentales (Diagnostic and Statistical Manual of Mental Disorders, DSM5) de la Asociación Estadounidense de Psiquiatría (American Psychiatric Association, o APA), todavía se considera una referencia a nivel mundial en la clasificación de los trastornos mentales para su posterior diagnóstico, estudio y tratamiento. Allen Frances, psiquiatra y presidente del grupo de trabajo de la versión anterior del texto, manifestó años antes su recelo hacia la ampliación de diagnósticos de la $5^{\text {a }}$ edición de la denominada biblia de la psiquiatría: "Será una 
bonanza para la industria farmacéutica, pero a costa de un enorme sufrimiento para los nuevos pacientes falsos positivos que queden atrapados en la excesiva amplia red del DSM-5" (Allen en Consejo General de la Psicología de España, 2013). Sin embargo, hoy en día siguen siendo innumerables las referencias en artículos científicos. Según Behar y Arancibia (2014): "El DSM-5 ha propuesto importantes innovaciones en los criterios diagnósticos de los trastornos de la conducta alimentaria (TCA) con implicancias en su prevalencia, desenlace y tratamiento".

De acuerdo al apartado 10 de este manual:

Los trastornos de la conducta alimentaria y de la ingesta de alimentos se caracterizan por una alteración persistente en la alimentación o en el comportamiento relacionado con la alimentación que lleva a una alteración en el consumo o en la absorción de los alimentos y que causa un deterioro significativo de la salud física o del funcionamiento psicosocial (DSM-5, 2014).

Aunque la evidencia preliminar basada en la propuesta del DSM-5 muestra una mayor proporción de personas que sufren anorexia nerviosa y bulimia nerviosa respecto al total de la población en estudio (Behar y Arancibia, 2014), conviene señalar la nueva incorporación del trastorno por atracón como TCA específico, lo que para Hidalgo y Rodríguez (2013) "supone adecuar los comportamientos de ingesta impulsiva a la realidad clínica y establecer la adecuada importancia clínica que presentan dichos comportamientos". Según el manual, se diferencian de las personas con bulimia nerviosa en que no restringen su dieta entre los episodios de pérdida de control (DSM-5, 2014). También aparecen en la clasificación el trastorno evitativo/restrictivo de la ingesta alimentaria (observado especialmente en niños), la pica (ingestión persistente de sustancias no nutritivas y no alimentarias), la rumiación, el trastorno purgativo y el síndrome del comer nocturno (DSM-5, 2014).

Las tres características diagnósticas básicas de la anorexia nerviosa definidas por este manual son "la restricción de la ingesta energética persistente que conlleva una pérdida de peso, el miedo intenso a engordar y la alteración de la forma de percibir el peso y la constitución propios". Y distingue entre la de tipo restrictivo, en la que "la pérdida de peso es debida sobre todo a la dieta y al ejercicio excesivo" y la de tipo con atracones/ purgas, que incluyen "episodios recurrentes de atracones y purgas mediante vómitos autoprovocados y el uso incorrecto de laxantes, diuréticos o enemas" (DSM-5, 2014).

Sobre los individuos con bulimia nerviosa, afirma que muestran "episodios recurrentes de atracones, utilizan comportamientos inapropiados para evitar ganar peso y están excesivamente preocupados por el peso y la constitución corporal", pero a diferencia de los pacientes con anorexia tipo atracones, "mantienen un peso corporal igual o mayor que el límite inferior normal” (DSM-5, 2014).

El otro gran manual de referencia internacional es publicado por la Organización Mundial de la Salud (OMS). La nueva versión de la Clasificación Estadística Internacional de Enfermedades y Problemas Relacionados con la Salud (CIE-11), presentada en Junio de 2018, no entrará en vigor hasta el 1 de enero de 2022 (Consejo General de la Psicología de España, 2018), por lo que nos remitiremos al anterior texto para nuestro estudio. La categoría de los Trastornos de la conducta alimentaria, código F50, aparece incluida en el capítulo de Trastornos del 
comportamiento asociados a disfunciones fisiológicas y a factores somáticos (F50F59).

En dicho manual se define la anorexia nerviosa como:

Trastorno caracterizado por una pérdida deliberada de peso, inducida y mantenida por el paciente [...] persiste un pavor ante la gordura y la flacidez de las formas corporales, a modo de ideas sobrevaloradas intrusivas, y el paciente se impone a sí mismo un límite máximo de peso bajo. Entre los síntomas incluyen "una dieta restrictiva voluntaria, ejercicio físico excesivo, inducción del vómito o purgas intestinales y uso de anorexígenos y diuréticos (CIE-10, 2000).

La bulimia nerviosa es definida como "Síndrome caracterizado por episodios repetidos de ingesta excesiva de alimentos y una preocupación excesiva por el peso corporal, que conducen a un patrón de atracones seguidos de vómitos o uso de purgantes." Añade que puede dar lugar a "trastornos del equilibrio electrolítico y a complicaciones somáticas" (CIE-10, 2000). Entre la categoría de Otros trastornos de la conducta alimentaria incluye la pérdida psicógena del apetito y la pica en adultos.

A pesar de la precisión de estas clasificaciones, diversos psiquiatras han comprobado que los TCA no son compartimentos estancos sino que evolucionan con frecuencia hacia distintas formas. Numerosos pacientes inicialmente diagnosticados de anorexia, presentan con el tiempo los síntomas de la bulimia, produciéndose de este modo un estado mixto (Behar y Arancibia, 2014).

Gonzalo Morandé Lavin, uno de los principales impulsores de la creación de unidades específicas de trastornos alimentarios en España, como la del Hospital Infantil Universitario Niño Jesús, precisaba sobre los calificativos de "nerviosa" y "mental":

En gran medida, el origen de la patología radica en el desarrollo de la corteza central del cerebro. Pero si bien en el albor de la anorexia está la resistencia a dejar la infancia, no es sólo la respuesta a una querencia. [...] Hay un importante componente genético, como sucede con todas las enfermedades, y hay causas ambientales que las precipitan y razones metabólicas que las llevan a manifestarse (Morandé en Zudaire, 2010).

\section{OBJETIVOS E HIPÓTESIS DE INVESTIGACIÓN}

La hipótesis de la investigación es que sólo un pequeño porcentaje de las obras de cine comercial que abordan el tema de los trastornos alimentarios se preocupa de presentar una versión real de la enfermedad, en toda su complejidad, y en su lugar reproducen una serie de lugares comunes, especialmente vinculados a la fuerza de voluntad personal de los protagonistas enfermos como principal pronóstico de su curación.

Con el propósito de corroborar o desestimar esta hipótesis, el objetivo principal de la investigación es el estudio y análisis de los ejemplos cinematográficos más relevantes, cuyo argumento se centra en casos de trastornos alimentarios. Este empeño general se condensa en varios objetivos más concretos:

- Análisis de contenido del argumento general, para observar si el film es realista o simplifica la realidad que presenta. Se estudiará con especial 
atención si la película ofrece alguna causa como origen de la enfermedad, si la descripción de los síntomas es coherente, o si la gravedad de cada caso se muestra de forma creíble, es decir, si la resolución del conflicto es verosímil en función de sus características.

- Análisis de contenido de los personajes principales y secundarios afectados por un trastorno, para observar si se repiten patrones comunes en su personalidad, o si por el contrario, se trata a cada uno de forma individualizada.

- Análisis de la reacción de la sociedad ante el problema.

\section{MÉTODOLOGÍA DE INVESTIGACIÓN}

En este apartado es esencial explicar dos puntos: En primer lugar es necesario exponer cómo se ha llevado a cabo el análisis de contenido de cada película. Y en segundo, cómo se ha elaborado la lista de películas a analizar, es decir, qué criterio se ha adoptado para delimitar la muestra de los materiales.

En cuanto al análisis de cada película, y siguiendo los objetivos que se han descrito en el apartado anterior, se busca estudiar qué tipo de historia se presenta. Es decir, partiendo de la base de que se trata de ficciones, si se ofrece una imagen alterada o edulcorada de la realidad, o se expone como un caso concreto de una realidad más compleja. Con el propósito de ser lo más objetivos posibles, se ha elaborado una ficha para cada película en la que se describe la personalidad de los personajes con trastornos, y su relación con el resto de individuos en el film. Los parámetros que contiene son:

- Personaje protagonista/ secundario: Se entiende que esta lista de características hay que completarlas para cada uno de los personajes de la película. Algunas de ellas tendrán sólo uno, mientras que en otras serán más numerosos.

- Edad y género del personaje.

- Apariencia física: es importante conocer si el intérprete escogido para el papel es una persona atractiva, lo más habitual en el cine comercial, o por el contrario se ha optado deliberadamente por un rostro más convencional. Esta información no sólo es relevante para analizar el grado de realismo, sino para entender qué idea previa recibe la sociedad de estos enfermos, ya que una de sus principales motivaciones tiene que ver con la estética y la percepción de su propio cuerpo.

- Sintomatología: se trata de saber si la información que se ofrece sobre sus síntomas es vaga o concreta, si es coherente, o incluso si el diagnóstico de la enfermedad es explícito.

- Consecuencias: Qué efectos tiene el trastorno en la vida del personaje y aquellos que le rodean.

- Pronóstico: En aquellos casos en los que la trama sigue el progreso de la enfermedad, se estudia si el personaje consigue completar su curación o por lo menos acepta finalmente la terapia.

- Juicio de valor sobre el personaje: Se valora la imagen que los creadores presentan como positiva, negativa o neutra. 
- Existencia de materiales anteriores: Se anota si la historia se basa en hechos reales, o si es una adaptación de una obra literaria previa como una novela o libreto teatral.

Además, se ha elaborado una ficha técnica con los apartados más destacados de cada film, incluyendo al equipo participante en la cinta.

En cuanto a la delimitación de la lista de películas, es evidente que lo deseable es contar con una muestra lo más amplia posible. En un principio, dado el altísimo número de estrenos que se suceden sin descanso ${ }^{2}$, se decidió acotar la lista de materiales a los últimos diez años, y únicamente analizar los ejemplos más conocidos desde el punto de vista mediático, puesto que lo que se estudia es precisamente su repercusión sobre el resto de la sociedad. Eso descarta una cierta cantidad de títulos, que por su escaso éxito no son conocidos, y por tanto tampoco son importantes si de lo que se trata es de valorar su impacto sobre el público. Sin embargo, después se comprobó que la lista de materiales audiovisuales que componían la muestra era muy escasa, pues en contra de las previsiones, se descubrió que había pocas producciones dedicadas a estos temas, por lo que se amplió el rango temporal hasta los últimos veinte años. También se han incluido varios cortometrajes que han tenido éxito en festivales cinematográficos ${ }^{3}$.

En cambio, se han excluido las producciones de largometrajes exclusivamente televisivos, las series o los anuncios. Estos materiales sí son relevantes puesto que son en gran parte modeladores de la opinión pública, y deberían ser analizados en posteriores investigaciones, pero quedan fuera de este estudio.

De todas formas, la carrera de los productos cinematográficos es larga, y lo que comienza como un proyecto concebido para su estreno en salas, continúa su vida en la televisión generalista o en plataformas de pago. Por ejemplo, la película de To The Bone se estrenó con gran éxito en el Festival de Sundance, y fue después cuando Netflix la compró por 8 millones de dólares para distribuirla a través de su plataforma online (Fleming, 2017).

En resumen, se ha seguido un análisis de contenido de acuerdo a la definición de Kerlinger de 1986 (en Wimmer y Dominick, 1996, p. 170), adoptando "una forma sistemática, objetiva y cuantitativa". Es decir, la selección de la muestra se ha llevado a cabo mediante un procedimiento normalizado, tratando de igual manera todos los filmes analizados, con reglas inequívocas para la clasificación de las variables. Todo ello combinado con el análisis cualitativo acerca del estilo narrativo de las películas y su calidad artística y técnica.

\footnotetext{
${ }^{2}$ Según un informe de la Unesco de 2015, si nos ceñimos únicamente a los 15 países con la industria cinematográfica más potente del mundo, cada año se producen más de 7000 películas (UNESCO Institute for Statistics, 2015).

${ }^{3}$ Aunque los cortometrajes no tienen mucha difusión, y por tanto influencia sobre el público en general, algunos casos concretos como los que hemos seleccionado, sí han logrado repercusión en festivales, un lugar de influencia importante sobre otros autores cinematográficos, es decir, que a la postre terminan influyendo sobre otros generadores de opinión y por tanto, marcan las futuras tendencias en los medios.
} 


\section{RESULTADOS DE INVESTIGACIÓN}

\subsection{Ficción}

\subsubsection{To the bone (2017)}

Dirección y guion: Marti Noxon

Producción: Sparkhouse Media \& Mockingbird Pictures en asociación con otras productoras.

Distribución: Netflix

Género: Drama

Duración: 107 min.

Nacionalidad: Estadounidense

Se cuenta la historia de Ellen, una joven con anorexia, y la terapia que la mantiene interna en una casa junto con otros pacientes. Al principio del film se hace una advertencia escrita en la que se dice literalmente que: "Esta es una película hecha con y por personas que han sufrido de trastornos alimentarios, e incluye descripciones realistas que quizá puedan ser demasiado para algunos espectadores"4.

Es conocido que tanto su directora y guionista Marti Noxon, como la actriz protagonista, Lily Collins, han sufrido en el pasado trastornos alimentarios (IMDb, 2018). Y efectivamente se nota que las creadoras entienden del tema puesto que tanto la sintomatología como el tratamiento médico son perfectamente verosímiles. Quizá peca de un excesivo sentimentalismo, y de forma predecible, termina con un final feliz a pesar de estar al borde de la muerte. Sin embargo, se percibe el esfuerzo por buscar activamente el realismo. Entre otros detalles reseñables, se encuentra un personaje masculino aquejado de anorexia, lo que rompe el tópico de que es una enfermedad exclusivamente femenina. De hecho, se manejan datos que indican que hasta un $30 \%$ de los afectados son hombres (NEDA Feeding Hope, 2018a). Aunque en el manual DSM-5 de la APA (American Psychiatric Association) apuntan que entre la población clínica existe una proporción entre mujeres y hombres de aproximadamente 10:1 (DSM-5, 2014). Sin embargo, estas cifras no son contradictorias ya que una de ellas se refiere a aquellos pacientes ya diagnosticados y en tratamiento y el otro porcentaje, a los que todavía no han ido al médico.

\subsubsection{Little Miss Perfect (2016)}

Dirección y guion: Marlee Roberts

Producción: Face your beast

Género: Drama

Duración: 82 min.

Nacionalidad: Estadounidense

\footnotetext{
${ }^{4}$ Traducción del original en inglés: "This film was created by and with individual who have struggled with eating disorders, and it includes realistic depictions that may be challenging for some viewers" (To the bone, Marti Noxon, 2017).
} 
La película narra cómo una estudiante de secundaria de espíritu perfeccionista comienza a bajar de peso como medida para controlar su vida, ante las inseguridades propias de la adolescencia, una madre ausente y un padre nada involucrado en la educación de su hija. La directora, que estuvo al borde de padecer anorexia, llevó a cabo una investigación previa con un psicólogo infantil de la Universidad de Nueva York (Robinson, 2016). Se trasluce un interés por mostrar los matices reales del trastorno sin idealizarlos, con conductas autodestructivas incómodas de ver en pantalla. También advierte de la peligrosidad de internet en mentes poco formadas. La actriz protagonista es la hermana de la realizadora.

\subsubsection{Min lilla syster (2015)}

Dirección y guion: Sanna Lenken

Producción: ARTE, Film i Väst, Fortune Cookie Filmproduktion, Sveriges Television (SVT), Tangy

Género: Drama

Duración: 95 min.

Nacionalidad: Sueca

La trama se resume en una patinadora con anorexia que intenta ocultar el problema hasta entrar en crisis. Pero en esta interesante película lo novedoso consiste en que el personaje protagonista no es la enferma, sino su hermana pequeña. Todo se ve a través de su punto de vista, una mirada inocente, perdida en un mundo adulto, desagradable y peligroso.

\subsubsection{Abzurdah (2015)}

Dirección y guion: Daniela Goggi

Guion: Daniela Goggi, Alejandro Montiel y Alberto Rojas Apel. Basado en la autobiografía de Cielo Latini

Producción: Fénix Contenidos Audiovisuales, Haciendo Cine

Género: Drama

Duración: 89 min.

Nacionalidad: Argentina

No se concede mucho tiempo para tratar el trastorno alimentario, sino que parece un síntoma más dentro del comportamiento autodestructivo de una adolescente que sufre en una relación amorosa, y que además de no comer, incluye las autolesiones $y$ finalmente el suicidio.

\subsubsection{Starving in Suburvia (2014). Otro título: Thinspiration}

Dirección y guion: Tara Miele

Producción: Indy Entertainment

Género: Drama

Duración: 84 min.

Nacionalidad: Estadounidense

Se cuenta la historia de una adolescente que, inspirada por una página web de culto a la anorexia, va enfermando progresivamente. Este es uno de los ejemplos 
más característicos de los encontrados en esta investigación, en los que los tópicos dominan el discurso, pues más que un film sobre anorexia, se parece a una película de terror, tanto en su estética visual como en su contenido. Los pensamientos obsesivos por adelgazar toman literalmente forma de pesadillas, e incluso se refieren a la voz de su cabeza como el demonio. La doctora no se diferencia mucho de un exorcista cuando en una sesión de terapia le sugiere que es la voz de la muerte. No obstante, al final, la protagonista consigue curarse, después de que su hermano, aparentemente sano, muera de un ataque al corazón producido por su propia anorexia que llevaba en secreto. Este hecho, es decir, que la víctima mortal sea un hombre, sería el único detalle destacable por encima de esta visión absolutamente estereotipada y oportunista de los trastornos alimentarios.

\subsubsection{The Road Within (2014)}

Guion y dirección: Gren Wells

Basada en una obra de teatro de Florian David Fitz

Producción: Amasia Entertainment y Troika Pictures en asociación con otras productoras

Género: Drama, comedia

Duración: 100 min.

Nacionalidad: Estadounidense

Roadmovie en la que tres personajes con problemas mentales huyen de la clínica donde estaban recibiendo tratamiento. Uno de ellos es una chica anoréxica que termina en el hospital, al final de la película, después de un ataque al corazón. Más que los trastornos alimentarios, el tema central del film son los problemas mentales, en su sentido amplio. Sin embargo, en esta emotiva historia, bien realizada, se plantean preguntas interesantes, ingenuas y a la vez directas entre los protagonistas, como por ejemplo: “¿por qué no comes?”.

\subsubsection{Likeness (2013)}

Dirección y guion: Rodrigo Prieto

Producción: Candescent Films, Idealogue, Little Minx

Género: Drama

Duración: 8 min.

Nacionalidad: Estadounidense

Cortometraje de vocación puramente estética, lo que se explica en parte dado que el director es un extraordinario director de fotografía. Se narra una fiesta desde el punto de vista deformado de una joven que ve a todas las personas delgadas y bellas, menos a ella misma. Ante la visión de pesadilla que le devuelve el espejo su única salida es vomitar. Sin embargo, esta ficción más bien parece un spot innecesariamente alargado, sin interés desde el punto de vista de la investigación, pues la enfermedad es una simple excusa para un despliegue técnico y visual. Sólo los créditos duran 2 minutos y medio, la mitad que el propio corto de 5 minutos.

\subsubsection{Maledimiele (2011)}

Dirección: Marco Pozzi 
Guion: Paola Rota

Producción: 3Xtreper

Género: Drama

Duración: 106 min.

Nacionalidad: Italiana

Una adolescente de quince años que mantiene su enfermedad en secreto, convive con unos padres sin apenas relación. Tras un viaje escolar, se desmaya por la falta de alimento y es llevada por su madre a una psicóloga.

El largometraje pretende ser una obra a medio camino entre el esteticismo y el cine comercial, lo que en ocasiones resulta fallido. Hay un intento de narrar los orígenes y efectos de la enfermedad, sin que los personajes lo hablen de forma explícita, pero a veces resulta simplista, como cuando parece identificarse a la abuela como una mala influencia. Según Morandé Lavín "tres décadas de estudios en profundidad sobre los trastornos y los estudios comparados nos han llevado a la conclusión de que la familia puede trasmitir la predisposición, pero nunca originar el trastorno" (Zudaire, 2010).

\subsubsection{Malos hábitos (2007)}

Dirección: Simón Bross

Guion: Ernesto Anaya y Simón Bross

Producción: Altavista Films, García Bross \& Asociados y otras productoras.

Género: Drama

Duración: 103 min.

Nacionalidad: Mexicana

La trama narra tres historias entrecruzadas: una monja que está convencida de que con su ayuno salvará al mundo del segundo diluvio, una madre anoréxica que se avergüenza de la apariencia física de su hija y le impone dietas pautadas por dudosos profesionales, y el padre de la niña, que se siente atraído por una estudiante que disfruta enormemente de la comida. El director utiliza los TCA como excusa para retratar a personajes extremos pero su sintomatología, reúne una amplia gama de comportamientos inapropiados que son comunes en numerosos pacientes: purgas, ayuno, ejercicio excesivo, atracones, uso excesivo de fármacos, masticación de desperdicios buscados en la basura... La película, que mezcla tintes de realismo mágico sin gran lucimiento, se ideó a partir de una noticia verídica sobre la corrosión de las tuberías de un colegio debido a los vómitos sucesivos de las alumnas (Crónica, 2007).

\subsubsection{Contracuerpo (2005)}

Dirección y guion: Eduardo Chapero-Jackson

Producción: Prosopopeya Producciones S.L.

Género: Drama

Duración: 17 min.

Nacionalidad: Española

Este cortometraje, que fue nominado a los premios Goya, recurre al tema de las obsesiones físicas sin adentrarse en la realidad del trastorno. Una chica adelgaza 
hasta lograr introducirse en un maniquí y ser contemplada en un escaparate. El objetivo del autor no parece ser la verosimilitud de la trama sino más bien la espectacularidad de las imágenes.

\subsubsection{Primo amore (2004)}

Dirección: Matteo Garrone

Guion: Matteo Garrone, Massimo Gaudioso, Vitaliano Trevisan sobre la novela autobiográfica de Carlo Mariolini, II cacciatore di anoressiche

Producción: Fandango y Medusa

Género: Drama

Duración: 100 min.

Nacionalidad: Italiana

Largometraje oscuro sobre la obsesión de un orfebre por lograr su ideal de mujer perfecta. De calidad notable, seleccionado por el Festival de Cine de Berlín, nos adentra en la peligrosa relación de un hombre que manipula a su pareja imponiéndole una dieta férrea hasta provocarle un trastorno alimentario. Garrone, que lograría fama mundial unos años más tarde con Gomorra, se sintió identificado con el protagonista por la presión que ejerció sobre la actriz, que sufrió secuelas psicológicas tras el rodaje (Paternò, 2004).

\subsubsection{Hunger Point (2003)}

Dirección: Joan Micklin Silver.

Guion: Deborah Amelon, basada en una novela de Jillian Medoff

Producción: Jaffe/Braunstein Films

Género: Drama

Duración: 100 min.

Nacionalidad: Estadounidense

Este film, de difusión principalmente televisiva, combina los tópicos más enraizados de la enfermedad con los estereotipos machistas. Y eso que, como en la casi totalidad de los ejemplos analizados, está dirigido por una mujer, Joan Micklin, artista que gozó de cierto prestigio en sus inicios. Por un lado se sugiere que el origen de los trastornos del personaje con anorexia se puede localizar directamente en el comportamiento de la madre durante su infancia, algo muy discutido por los expertos (NEDA Feeding Hope, 2018b). Por otro lado, gran parte del metraje se invierte en la necesidad, supuestamente vital, de un novio para la protagonista, una búsqueda cuyo final feliz se percibe incluso como una protección frente a la enfermedad.

\subsection{Documental}

\subsubsection{Thin (2006)}

Dirección: Lauren Greenfield

Producción: HBO

Género: Documental

Duración: 102 min.

Nacionalidad: Estadounidense 
Este documental narra la vida de cuatro mujeres en un centro hospitalario especializado en tratamiento de trastornos alimentarios. Sin voz en off, con apenas algún cartel informativo, se limita a seguir a las enfermas en su día a día, en el comedor, en la terapia, en su dormitorio. Intenta no emitir juicios de valor, sino tan sólo mostrar la lucha constante por la supervivencia. En lugar de informar sobre detalles médicos de las protagonistas, se concentra en sus sentimientos, con un estilo cercano y al mismo tiempo realista. Aunque, quizá precisamente por eso, al final es de una crudeza extrema pues lo único que deja es una huella de fracaso y depresión. En este sentido, la profesora Cynthia M. Bulik, profesora de desórdenes alimentarios de la UNC School of Medicine declaró: "La película analiza pacientes con casos más graves. [...] Al centrarse en estos casos difíciles, crea la sensación de que el tratamiento para los trastornos de la alimentación es inútil y que hay pocas esperanzas de recuperación. Pero hay una ciencia real detrás del tratamiento para los trastornos de la alimentación, y las personas con trastornos de la alimentación pueden mejorar y lo hacen" (2006).

\subsubsection{Super Size Me (2004)}

Guion y dirección: Morgan Spurlock

Producción: The Con, Kathbur Pictures

Género: Documental

Duración: $100 \mathrm{~min}$.

Nacionalidad: Estadounidense

Este famoso documental, éxito de taquilla, está narrado en primera persona por su director, emulando el estilo desenfadado puesto de moda por Michael Moore. Se ocupa sobre todo de las cadenas de comida rápida, pero extiende el foco hasta ocuparse de los trastornos alimentarios, de los que también culpabiliza en parte a estas empresas. Se habla de adicción a la comida de la misma forma que la adicción a las drogas, mencionando los receptores opiáceos en el cerebro que se activan con la ingesta. Entrevista a varios representantes médicos y legales en la autodenominada lucha contra la epidemia de obesidad en Estados Unidos con varias conclusiones muy polémicas. Por ejemplo Jacob Sullum, editor de la revista Reason, se atreve a decir, medio en broma medio en serio, que ahora está socialmente aceptado meterse con los fumadores, pero que en breve lo será con los gordos.

\subsection{Ejemplos descartados}

Algunos casos que estaban en la muestra inicial se han descartado finalmente por no cumplir la condición de que los trastornos alimentarios fueran uno de los temas centrales de su trama. Por ejemplo:

Fast Food Nation (2006): Tiene más que ver con una denuncia del consumo de carne a nivel global y sus consecuencias económicas, que con los desórdenes mentales en esa área.

Feed (2006): Es la historia de un asesino en serie que se dedica a alimentar a sus víctimas hasta la muerte. De la misma forma que utiliza los tópicos menos realistas, pero más escandalosos, de las relaciones sadomasoquistas, también se aprovecha de los aspectos más desagradables de los trastornos alimentarios para aterrorizar al 
espectador. Se ha descartado porque la verdadera enfermedad, que en el fondo es mucho más terrible y cotidiana que esta ficción, apenas es una excusa.

Black Swan (2010): Trata sobre una bailarina que va perdiendo progresivamente la cordura. Aunque existen episodios de anorexia y otros problemas, que se repiten con demasiada frecuencia en la profesión, se descarta porque en la trama apenas ocupan un lugar anecdótico.

Gordos (2009): El director Sánchez Arévalo cuenta en esta interesante comedia las vicisitudes de varios personajes que acuden a un grupo de terapia para bajar de peso. No se ha incluido en el estudio ya que no sufren trastornos de la conducta alimentaria propiamente dichos, sino más bien, cierta ansiedad que satisfacen con la comida.

Wall-E (2008): En este futuro apocalíptico de Pixar, los humanos se dedican exclusivamente al ocio: un estilo de vida tan sedentario, que les provoca una obesidad mórbida hasta el punto de que todos necesitan ir en silla de ruedas. Pero no se refleja un trastorno alimentario como enfermedad, sino una decadencia generalizada de la especie.

Cleopatra (2003): Este film argentino narra las peripecias de una joven actriz y su nueva confidente, una mujer madura cansada de su vida monótona, que emprenden un viaje para escapar de todo. Los vómitos son el único síntoma que presenta la protagonista y apenas aparecen en dos secuencias, dando a entender que se trata de un reflejo de su insatisfacción vital, no de un trastorno más profundo.

Girl, Interrupted (1999): Esta película se cita en algunas listas como un ejemplo de contenido audiovisual sobre la anorexia, pero lo cierto es que apenas se aborda el tema de forma tangencial en un personaje muy secundario.

También se ha descartado el cortometraje español Del Flaubert que leíste un día gris (1997), del director Pablo Valiente. A pesar de ser un ejemplo de una calidad y relevancia notables, escapaba al marco temporal del estudio.

\section{DISCUSIÓN}

Después de recopilar y analizar los datos de los filmes que componen la muestra, se ha llegado a unos resultados inesperados.

La hipótesis que se planteaba al principio, es decir, que en la sociedad hay un desconocimiento general de los problemas mentales, y que eso se manifestaría en que la mayor parte de las películas que tratan este tema lo harían repitiendo la visión de los tópicos más comunes sobre la anorexia, se ha confirmado sólo en parte y de una forma impredecible. Por un lado, es cierto que una gran proporción de las películas analizadas son estereotipadas, y muestran una osada falta de información sobre los trastornos alimentarios que intentan representar (en concreto el 45\%). Pero también es verdad que un porcentaje aún superior de los filmes de la muestra (el $55 \%$ ), se apartan de esa tendencia simplista, haciendo un esfuerzo muy meritorio por afrontar estos temas con la profundidad y delicadeza que se merecen. De hecho, algunos de esos proyectos combinan un dominio notable de los pormenores médicos, con un conocimiento íntimo del lado emocional de ese tipo de dolencias, lo que sugiere que los creadores 
involucrados lo hacen movidos por una historia personal de relación con la enfermedad, ya sea de forma directa o a través de un familiar muy cercano. Algunas directoras han confesado abiertamente que han sufrido esos síntomas en su propia vida, y que su objetivo era contribuir a ayudar a otros. Además, en esos casos especiales, suelen combinar las labores de escritura de guion y realización, lo que apoya la idea de la vinculación personal. Luego, el resultado estético puede variar, en función de la pericia técnica de la realización y de la interpretación, pero no se puede negar una voluntad por conseguir un producto de calidad.

Lo que no hay, y nos parece sorprendente, es un terreno intermedio. Ya suponíamos al principio de la investigación que habría abundantes ejemplos de películas deleznables llenas de tópicos, y en el extremo contrario alguna joya valiosa, con verdaderos personajes de carne y hueso. Lo que no anticipábamos es que no existiría prácticamente nada entre ambas alternativas, es decir, narraciones anodinas, o incluso mediocres, pero con ciertas aspiraciones de verosimilitud. Al final, éste es precisamente el panorama que se ha descubierto.

El tratamiento de los personajes, que era otro de los objetivos marcados en el estudio, está igualmente conectado con el carácter, realista o no, de la producción. Aquellos largometrajes con un franco interés por las personas que sufren esa dolencia, también se preocupan por hacer un retrato creíble de ellos, sin juicios de valor. En cambio, en las otras cintas que tan sólo se ocupan de la anorexia de forma anecdótica, son capaces hasta de convertir a los protagonistas en maniacos psicópatas.

Hay un aspecto de estos trastornos, y de la vida en general, particularmente difícil de trasladar al cine: el tiempo de transcurso de la enfermedad suele ser muy largo, y eso se conjuga mal con los cien minutos de metraje de media. La ficción tiene sus trucos para condensar historias extensas en un corto espacio, por ejemplo a través de elipsis que apuntan a distintas fases del relato, sin tener que mostrar el desarrollo completo. Pero eso tiene un límite, especialmente duro en aquellos ejemplos que intentan alejarse de los modelos del cine comercial, para acercarse a los casos reales, porque la biografía de estos enfermos es repetitiva, monótona, y llena de retrocesos. Además los espectadores suelen preferir finales concluyentes, en lugar de abiertos, lo que supone que los guionistas se ven obligados a responder de forma explícita a la pregunta de si la narración acaba bien o mal, casi en estos términos. ¿La protagonista se cura o vuelve a vomitar? ¿Se muere o sale del hospital? En cambio, hasta que evolucionaron los tratamientos específicos hace algunos años, en los trastornos alimentarios, al igual que con otras patologías como el alcoholismo, era infrecuente una curación definitiva. La recuperación era temporal si no había un esfuerzo permanente, sabiendo que en cualquier momento se podía recaer. En este sentido, Morandé Lavín realiza una precisión:

Como tantas otras enfermedades, puede ser recurrente y desarrollarse de nuevo treinta años después, pero cuando se da el alta a un paciente, está curado y puede hacer una vida normal. El tratamiento es largo, se necesitan tres o cuatro años en los que se procura que las recaídas se distancien hasta desaparecer, pero son muy pocos los enfermos que no logran curarse. Aunque claro, con tantos enfermos, pocos son muchos (Zudaire, 2010). 
Por otra parte, aunque este proyecto no estaba inicialmente previsto como una investigación de género, nos ha llamado la atención que la aplastante mayoría de las películas de la muestra han sido dirigidas por mujeres. Dado que la anorexia se asocia habitualmente al ámbito femenino, se podría pensar que los resultados no son en modo alguno sorprendentes, pues al ser un tema más cercano a ellas, era previsible anticipar que también habría una mayor proporción de mujeres tras las cámaras. Pero eso no sería más que una repetición de los estereotipos de género. En primer lugar porque los expertos insisten en denunciar que los hombres constituyen un tercio de los casos de trastornos alimentarios (NEDA Feeding Hope, 2018c), y que a causa de la doble vergüenza que sufren (por la propia enfermedad y por ser hombres los que la padecen), piden ayuda más tarde o con menos frecuencia, y por tanto el pronóstico suele ser mucho más grave. En segundo lugar porque hasta ahora el porcentaje de hombres directores, hablando de cualquier tema, tanto los que les son propios como los que no, es abrumador, superior al $90 \%{ }^{5}$ (Smith et al, 2018), por lo que ese mismo panorama podría reproducirse también aquí. Sin embargo, se observa justo lo contrario: de las 12 películas de ficción y 2 de documental, tan sólo 6 tienen a un director masculino, es decir que los resultados son muy distintos. $Y$ esos seis ejemplos masculinos son quizá los menos relevantes de la muestra pues dos son cortometrajes, y el resto sólo utiliza la enfermedad como telón de fondo exótico para su guion, sin demostrar verdadero interés.

No obstante, para debatir con rigor, hay que situar estas cifras en su contexto. Es necesario reconocer que la muestra no contiene un gran número de películas, a pesar de que, precisamente para ampliarla, se alargó el comienzo del periodo de estudio hasta el año 1998. Lejos de pensar que le resta valor, hay que tomar esa escasa cantidad como una de las revelaciones más importantes de la investigación, pues resulta extraordinario que una enfermedad que afecta al menos a un $3 \%$ de la población $^{6}$, apenas llegue al $0.0001 \%$ de las películas. Por supuesto que habrá muchos otros ejemplos de filmes que, de pasada, mencionen los síntomas o incorporen un personaje secundario afectado, pero el resumen es que, en el lapso de los últimos veinte años, únicamente se han realizado 14 largometrajes que incluyan a los trastornos alimentarios como un tema importante dentro de su trama ${ }^{7}$, lo que indica que no es algo que le preocupe demasiado a la sociedad.

En cualquier caso, el hecho de contar con una muestra con pocos ejemplos constituye uno de los límites del presente estudio. En el futuro, será necesario ampliar la investigación para analizar tanto los productos de ficción e información televisiva como la publicidad. En una prospección somera, no exhaustiva, se ha

\footnotetext{
${ }^{5}$ Según datos del estudio Inclusion in the Director's Chair? (Smith et al., 2018), que analiza las estadísticas de los últimos diez años, el porcentaje de películas dirigidas por mujeres es de media un mísero $4,3 \%$. Es verdad que esta cifra se refiere a las películas de mayor recaudación cada año, y que el porcentaje sube en el cine independiente, pero en todo caso nunca será superior al 15 o $20 \%$ de media, como sugiere el estudio Women On Screen and Behind the Scenes in Television (Lauzen, 2018).

${ }^{6}$ No existen datos conjuntos del total de afectados por los trastornos alimentarios, pero sí hay numerosos estudios que aportan estadísticas sobre anorexia $0.6 \%$, bulimia $0.5 \%$, trastorno por atracón $2.7 \%$, y muchos otros más. Es complicado para los investigadores dar con cifras fiables porque es una enfermedad que se tiende a ocultar (NEDA Feeding Hope, 2018c).

Es posible que, aunque se haya puesto todo el cuidado, se haya escapado algún caso de forma inadvertida. Además hay que considerar que sólo se han tenido en cuenta las cinematografías occidentales. De todos modos esa eventualidad no alteraría demasiado los números.
} 
comprobado que, en las series de televisión, mucho más ágiles a la hora de escribir, sí hay una mayor incidencia de estos casos, sobre todo en lo que respecta a las series destinadas al público femenino adolescente. Lo que por otro lado es lógico si se piensa que ahí es donde más incidencia tiene la enfermedad. Aunque no está claro si la televisión lo hace con intención de servicio público, o simplemente porque es un tema que le otorga cierta respetabilidad en la promoción de su marca de empresa.

\section{CONCLUSIONES}

Se cumplen los objetivos previstos en un principio, aunque la hipótesis sólo se confirma de forma parcial, pues dentro de la muestra estudiada, se combinan una serie de películas comerciales, plagadas de tópicos sobre la enfermedad, con otros casos en el extremo opuesto: cintas muy bien informadas sobre la sintomatología y el pronóstico, y que en lugar de presentar juicios de valor sobre los pacientes, intentan construir personajes complejos y realistas.

Un gran número de los filmes está dirigido y escrito por mujeres, en concreto un $57 \%$, dato no coincidente con las estadísticas más habituales en donde la media es de sólo un $4,3 \%$.

La muestra estudiada no es numerosa. En los últimos veinte años apenas se han producido unas cuantas películas que tengan a los trastornos alimentarios como uno de los temas centrales de su trama, lo que da una idea de que no es un asunto que interese a la industria cinematográfica, o simplemente, que no se considera que el drama de los afectados sea susceptible de convertirse en un buen y exitoso guion de cine.

En cualquier caso, esto significa que, para conocer en profundidad cuál es la visión que los medios audiovisuales transmiten sobre esta enfermedad, en el futuro convendría ampliar la muestra al resto de producciones de la televisión (tanto de ficción, TV movies y series, como de entretenimiento e información). Sobre todo, habrá que incluir un género importantísimo para la generación de opinión en la sociedad: la publicidad.

\section{BIBLIOGRAFÍA}

American Psychiatric Association (2014). DSM-5. Madrid: Editorial Médica Panamericana.

Behar, R. y Arancibia, M. (2014). DSM-V y los trastornos de la conducta alimentaria. Revista Chilena de neuro-psiquiatría, 52(1). Disponible en www.sonepsyn.cl

Bulik, C. (2006). Dying to Be Thin. ABC News. Disponible en https://abcnews.go.com/Health/story?id=2655900\&page $=1$

Consejo General de la Psicología de España (2013). El debate mundial generado por el DSM-5. Infocop Online. Disponible en http://www.infocop.es/view_article.asp?id=4587 
Consejo General de la Psicología de España (2018). La OMS publica la versión final de la CIE-11. Infocop Online. Disponible en

http://www.infocop.es/view_article.asp?id=7548

Crónica (2007). 'Hicimos Malos Hábitos para entretener, pero si una niña bulímica pide ayuda tras ver mi cinta, me doy por bien servido', dice Simón Bross, el director. La Crónica de Hoy. Disponible en http://www.cronica.com.mx/notas/2007/327700.html

Fleming, M. (2017). Netflix Making \$8 Million Deal For Lily Collins-Keanu Reeves Drama 'To The Bone'. Revista Deadline Hollywood. Disponible en https://deadline.com/2017/01/to-the-bone-lily-collins-keanu-reeves-netflix-martinoxon-1201893287/

Hidalgo, M. I. y Rodríguez, P. J. (2013). DSM-5. Manual diagnóstico y estadístico de los trastornos mentales. Últimas novedades 2013. Pediatría Integral, 461. Disponible en https://www.pediatriaintegral.es/wp-content/uploads/2013/xvii07/00/461462\%20Editorial\%207.pdf

IMDb. Internet Movie Database. Disponible en www.imdb.com

Lauzen, M. (2018). Women On Screen and Behind the Scenes in Television. Centre for the Study of Women in Television \& Film, San Diego State University. Disponible en https://womenintvfilm.sdsu.edu/wp-content/uploads/2018/09/201718_Boxed_In_Report.pdf Recuperado el 20 de Septiembre de 2018

NEDA Feeding Hope (2018a). Eating disorders in men and boys. Disponible en https://www.nationaleatingdisorders.org/learn/general-information/research-onmales

NEDA Feeding Hope (2018b). Busting the myths about eating disorders. Disponible en https://www.nationaleatingdisorders.org/busting-myths-about-eating-disorders

NEDA Feeding Hope (2018c). Statistics \& research on eating disorders. Disponible en https://www.nationaleatingdisorders.org/statistics-research-eating-disorders

Organización Mundial de la Salud (2000). CIE-10, Clasificación de los trastornos mentales y del comportamiento. Madrid: Editorial Médica Panamericana.

Robinson, A. (2016). Little Miss Perfect: An Adolescent's Descent into Anorexia. Eating disorder recovery specialists. Disponible en http://eatingdisorderspecialists.com/little-miss-perfect-capturing-adolescentsdescent-anorexia/

Paternò, C. (2004). El indigesto amor de Garrone. CineEuropa. Disponible en https://cineuropa.org/es/newsdetail/49653/

Smith, S., Choueiti, M. y Pieper, K. (2018). Inclusion in the Director's Chair? Gender, Race \& Age of Directors across. 1.100 Films from 2007-2017, Annenberg 
Inclusion Initiative. USC Annenberg School for Communication and Journalism. Disponible en http://assets. uscannenberg.org/docs/inclusion-in-the-directors-chair2007-2017.pdf

UNESCO Institute for Statistics (2015). Feature films - Total number of national feature films produced. Disponible en http://uis.unesco.org/

Wimmer, R. y Dominick, J. (1996). La investigación científica de los medios de comunicación. Una introducción a sus métodos. Barcelona: Bosch Casa Editorial.

Zudaire, M. (2010). Gonzalo Morandé Lavin, jefe de servicio de la Unidad de Psiquiatría y Psicología del Hospital Infantil Universitario Niño Jesús. Revista Fundación E Consumer. Disponible en

http://www.consumer.es/web/es/alimentacion/aprender_a_comer_bien/enfermeda d/2010/07/30/194676.php

\section{Películas}

Aronofsky, D. (2010). Black Swan. [Cinta cinematográfica]. EE.UU.: Fox Searchlight Pictures.

Bross, S. (2007). Malos hábitos. [Cinta cinematográfica]. México: Altavista Films, García Bross \& Asociados.

Chapero-Jackson, E. (2005). Contracuerpo. [Cinta cinematográfica]. España: Prosopopeya Producciones S.L.

Garrone, M. (2004). Primo amore. [Cinta cinematográfica]. Italia: Fandango y Medusa.

Goggi, D. (2015). Abzurdah. [Cinta cinematográfica]. Argentina: Fénix Contenidos Audiovisuales, Haciendo Cine.

Greenfield, L. (2006). Thin. [Cinta cinematográfica]. EE.UU.: HBO.

Lenken, S. (2015). Min lilla syster. [Cinta cinematográfica]. Suecia: ARTE, Film i Väst, Fortune Cookie Filmproduktion, Sveriges Television (SVT), Tangy.

Leonard, B. (2005). Feed. [Cinta cinematográfica]. Australia: All At Once, Becker Films International, Cutting Edge y Feed Productions.

Linklater, R. (2006). Fast Food Nation. [Cinta cinematográfica]. EE.UU.: Fox Searchlight Pictures, HanWay Films, BBC Films y RPC.

Mangold, J. (1999). Girl, Interrupted. [Cinta cinematográfica]. EE.UU.: Columbia Pictures Corporation, Red Wagon Entertainment y 3 Arts Entertainment.

Miele, T. (2014). Starving in Suburvia. [Cinta cinematográfica]. EE.UU.: Indy Entertainment. 
Micklin, J. (2003). Hunger Point. [Cinta cinematográfica]. EE.UU.: Jaffe/Braunstein Films.

Mignogna, E. (2003). Cleopatra. [Cinta cinematográfica]. Argentina: Televisión Federal (Telefe), Patagonik Film Group y Alquimia Cinema.

Noxon, M. (2017). To the bone. [Cinta cinematográfica]. EE.UU.: Sparkhouse Media \& Mockingbird Pictures.

Pozzi, M. (2011). Maledimiele. [Cinta cinematográfica]. Italia: 3Xtreper.

Prieto, R. (2013). Likeness. [Cortometraje]. EE.UU.: Candescent Films, Idealogue, Little Minx.

Sánchez Arévalo, D. (2009). Gordos. [Cinta cinematográfica]. España: Tesela Producciones Cinematográficas, Canal+ España, Filmanova y Televisión Española (TVE).

Spurlock, M. (2004). Super Size Me. [Cinta cinematográfica]. EE.UU.: The Con, Kathbur Pictures.

Stanton, A. (2008). Wall-E. [Cinta cinematográfica]. EE.UU.: Pixar Animation Studios, Walt Disney Pictures y FortyFour Studios.

Valiente, P. (1997). Del Flaubert que leíste un día gris. [Cortometraje]. España: Pablo Valiente P.C.

Wells, G. (2014). The Road Within. [Cinta cinematográfica]. EE.UU.: Amasia Entertainment y Troika Pictures. 